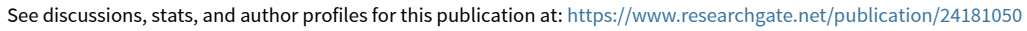

Three lanthanide complexes derived from itaconic acid and 2,2 '-bipyridine

Article in Acta Crystallographica Section C Crystal Structure Communications · April 2009

DOI: 10.1107//50108270109002534 - Source: PubMed

4 authors, including:

$$
\text { M. T. Garland }
$$

University of Chile

402 PUBLICATIONS 3,504 CITATIONS

SEE PROFILE 


\section{Three lanthanide complexes derived from itaconic acid and 2,2'-bipyridine}

\author{
Juan Carlos Muñoz, ${ }^{\text {a }}$ Ana María Atria, ${ }^{\text {b Maria Teresa }}$ \\ Garland $^{\mathrm{c}}$ and Ricardo Baggio ${ }^{\mathrm{d} *}$
}

anstituto de Química, Facultad de Ciencias Exactas y Naturales, Universidad de Antioquia, Medellín, Colombia, ${ }^{\mathbf{b}}$ Facultad de Ciencias Químicas y Farmacéuticas, Universidad de Chile, Casilla 233, Santiago, Chile, ${ }^{\mathrm{c}}$ Departamento de Física, Facultad de Ciencias Físicas y Matemáticas and CIMAT, Universidad de Chile, Santiago de Chile, Chile, and dDepartamento de Física, Centro Atómico Constituyentes, Comisión Nacional de Energía Atómica, Buenos Aires, Argentina Correspondence e-mail: baggio@cnea.gov.ar

The structures of three new polymeric lanthanide complexes, poly[[bis(2,2'-bipyridine)- $\mu_{4}$-itaconato-di- $\mu_{3}$-itaconato-digadolinium(III)] tetrahydrate], $\left\{\left[\mathrm{Gd}_{2}\left(\mathrm{C}_{5} \mathrm{H}_{4} \mathrm{O}_{4}\right)_{3}\left(\mathrm{C}_{10} \mathrm{H}_{8} \mathrm{~N}_{2}\right)_{2}\right] \cdot 4 \mathrm{H}_{2} \mathrm{O}\right\}_{n}$, (I), poly[diaqua (2,2'-bipyridine) di- $\mu_{3}$-itaconato- $\mu_{2}$-itaconatodigadolinium(III)], [ $\left.\mathrm{Gd}_{2}\left(\mathrm{C}_{5} \mathrm{H}_{4} \mathrm{O}_{4}\right)_{3}\left(\mathrm{C}_{10} \mathrm{H}_{8} \mathrm{~N}_{2}\right)\left(\mathrm{H}_{2} \mathrm{O}\right)_{2}\right]_{n}$, (II), and poly[[bis(2,2'-bipyridine)- $\mu_{4}$-itaconato-di- $\mu_{3}$-itaconato-diholmium(III)] dihydrate $],\left\{\left[\mathrm{Ho}_{2}\left(\mathrm{C}_{5} \mathrm{H}_{4} \mathrm{O}_{4}\right)_{3}\left(\mathrm{C}_{10} \mathrm{H}_{8} \mathrm{~N}_{2}\right)_{2}\right] \cdot 2 \mathrm{H}_{2} \mathrm{O}\right\}_{n}$, (III), have been solved from twinned specimens. Compound (I) presents a two-dimensional polymeric structure parallel to (011) built up around two independent nine-coordinated Gd centres displaying similar $\mathrm{GdO}_{7} \mathrm{~N}_{2}$ environments, with both $\mathrm{N}$-donor atoms in each provided by a chelating $2,2^{\prime}$ bipyridine (bpy) unit. The coordinating $\mathrm{O}$ atoms are from three different itaconate (ita) anions (itaconic acid is 2-methylidenebutanedioic acid). Compound (II) also presents two independent Gd centres (one ten- and the other eight-coordinated), but the overall formula and individual coordinations are different from those of (I). The chemical unit is in this case completed by one bpy ligand, three ita anions (one of them displaying a new, hitherto unreported, $\mu_{3}-O, O^{\prime}: O^{\prime}, O^{\prime \prime}: O^{\prime \prime \prime}$ binding mode) and two aqua ligands. The whole structure is built up around a twofold rotation axis passing through both cations, as well as through the centre of the bpy ligand and one of the ita anions, thus making only half of the chemical unit independent. Finally, compound (III) presents a single independent Ho centre, a bpy unit and one and a half ita anions (one of them bisected by a twofold rotation axis) in the asymmetric unit, plus two (disordered) nonbonded solvent water molecules. In compounds (II) and (III), those ita anions bisected by a symmetry element incompatible with the internal symmetry of the ligand exhibit disorder in the $\mathrm{C}=\mathrm{CH}_{2}$ group.

\section{Comment}

The generation of high-dimensional coordination polymers assembled from metal-organic compounds and characterized by open frameworks has been (and still is) an important branch of crystal engineering (see, for example, Eddaoudi et al., 2001), due to the expected potential properties of the eventual novel compounds, e.g. catalysis (Seo et al., 2000), ionexchange (Yaghi et al., 1997), gas absorption (Yaghi et al., 2003), and so on. While carboxylic acids have been extensively exploited in order to provide promising functional frameworks, aliphatic acids in particular do not seem to have been adequately explored [although for a recent report on the subject, see Zhang et al. (2006)], in spite of their well known<smiles>C=C(CC(=O)O)C(=O)O</smiles>

ita<smiles>[M]OC(=C)CC(=O)O[M]</smiles><smiles></smiles><smiles>C=C(CC1OO[M]1O)C1=CO1</smiles><smiles>[Y]C1OC(CC(=C)C2[Y1]O2)O1</smiles><smiles></smiles><smiles>[M]OC(=C)CC(=O)O[M]</smiles>

4

5<smiles>[M]OC(=C)CC(O[M])O[M]</smiles>

7

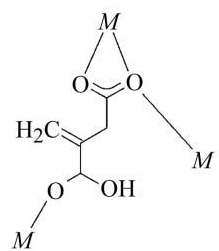

10

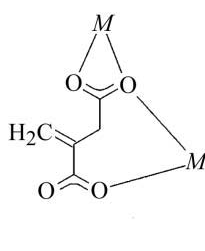

8

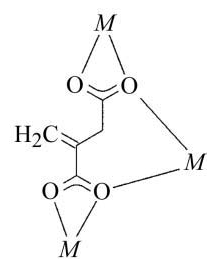

9 flexibility which would make them extremely suitable to achieve a variety of different architectures. One of these rather unexploited ligands is itaconic acid (hereinafter ita), the common name of methylenesuccinic acid (systematic name: 2-methylidenebutanedioic acid), an extremely flexible ligand which, because of its ability to bind through two carboxylic 
acid end groups, can provide an extensive variety of coordination modes.

In spite of this potential, there are only a limited number of reported complexes containing the coordinated ita anion. A survey of the Cambridge Structural Database (2008 Version; Allen, 2002) showed that there are nine such complexes in total to date, three of them with the ligand bound to transition

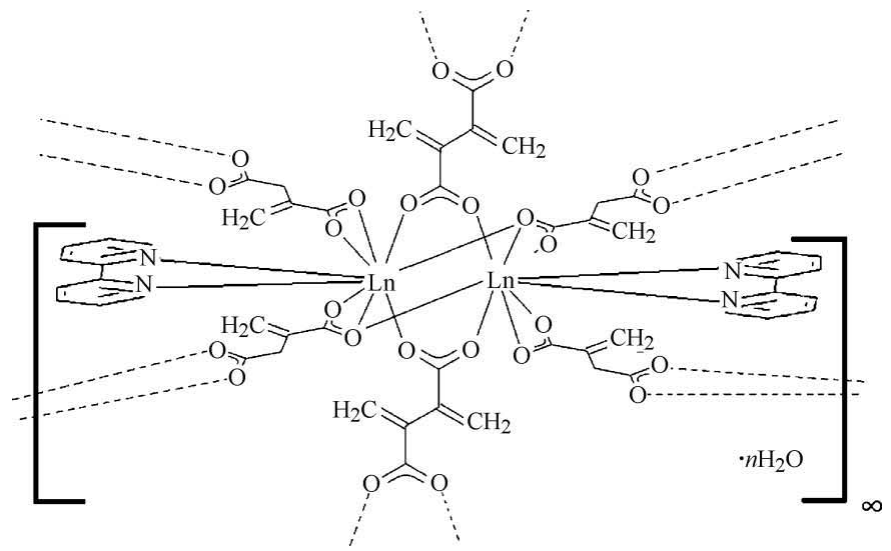

(I) $\mathrm{Ln}=\mathrm{Gd}, n=4$

(III) $\mathrm{Ln}=\mathrm{Ho}, n=2$

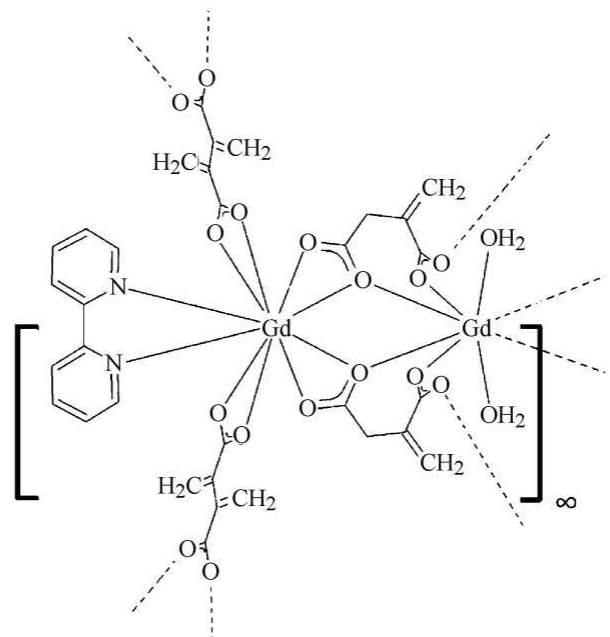

(II)

metals ( $\mathrm{Ni}^{\mathrm{II}}$ : Burrows, Harrington et al., 2004; $\mathrm{Zn}^{\mathrm{II}}$ : Burrows, Donovan et al., 2004; and Cd ${ }^{\mathrm{II}}$ : Contreras et al., 1997), one to an alkaline earth ( $\mathrm{Ba}^{\mathrm{II}}$ : Briceño et al., 1999) and five to lanthanides ( $\mathrm{La}^{\mathrm{III}}, \mathrm{Eu}^{\mathrm{III}}, \mathrm{Dy}^{\mathrm{III}}, \mathrm{Er}^{\mathrm{III}}$ and $\mathrm{Yb}^{\mathrm{III}}$ : Liu et al., 2005). Surprisingly, in spite of this limited number of complexes, as many as ten different coordination modes could be distinguished for the ligand (coordination modes 1-10, shown in the scheme above).

The extended character of the molecule and its doubleended binding ability render it able to fulfil an efficient bridging role in (usually complex) three-dimensional structures in which voids and cavities can easily build up. Looking for new compounds of this kind, we have tried to synthesize via hydrothermal methods some lanthanide complexes bearing

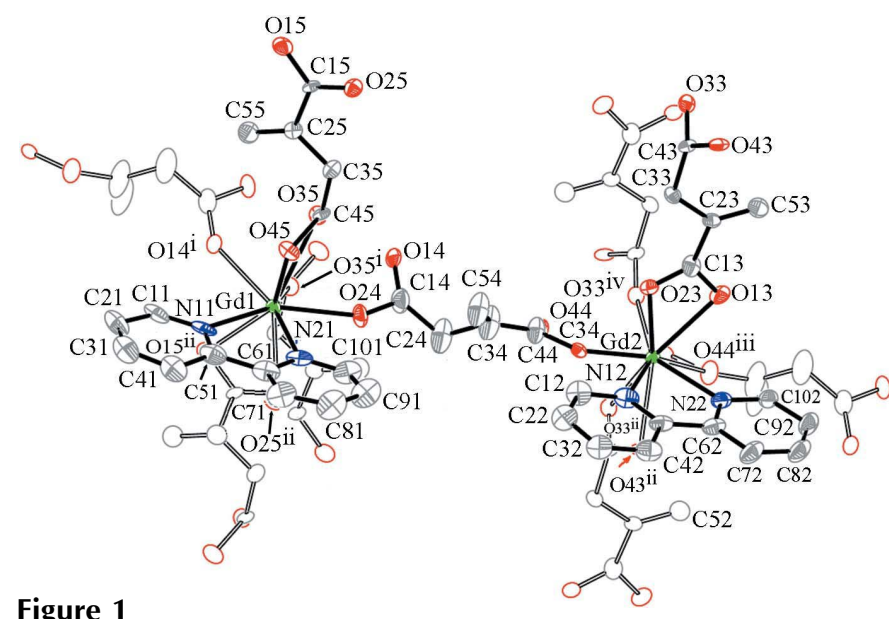

The two Gd coordination polyhedra in (I), showing the atom-numbering scheme. Displacement ellipsoids are drawn at the $30 \%$ probability level and $\mathrm{H}$ atoms have been omitted for clarity. [Symmetry codes: (i) $-x+1$, $-y,-z$; (ii) $x+1, y, z$; (iii) $-x+1,-y+1,-z-1$; (iv) $-x,-y+1,-z-1$.]

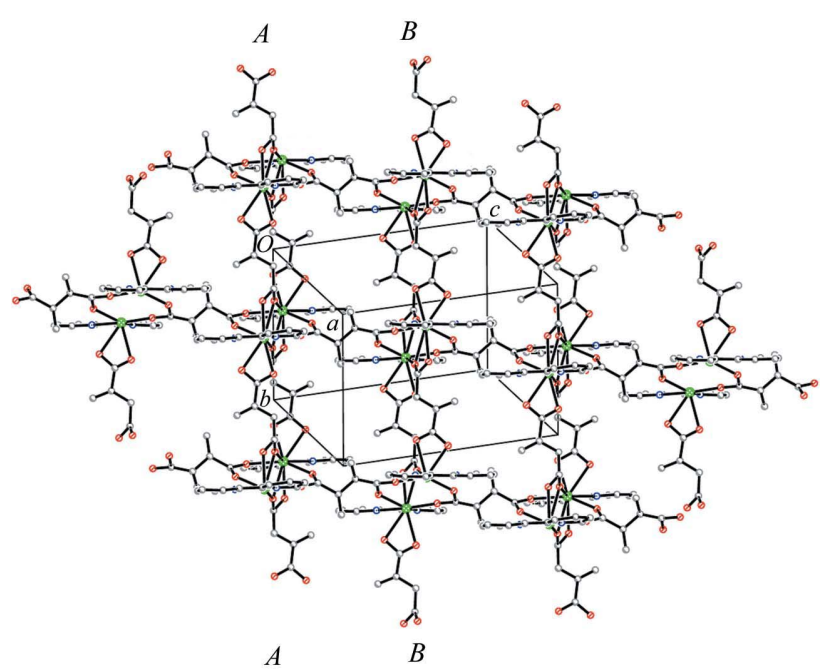

(a)

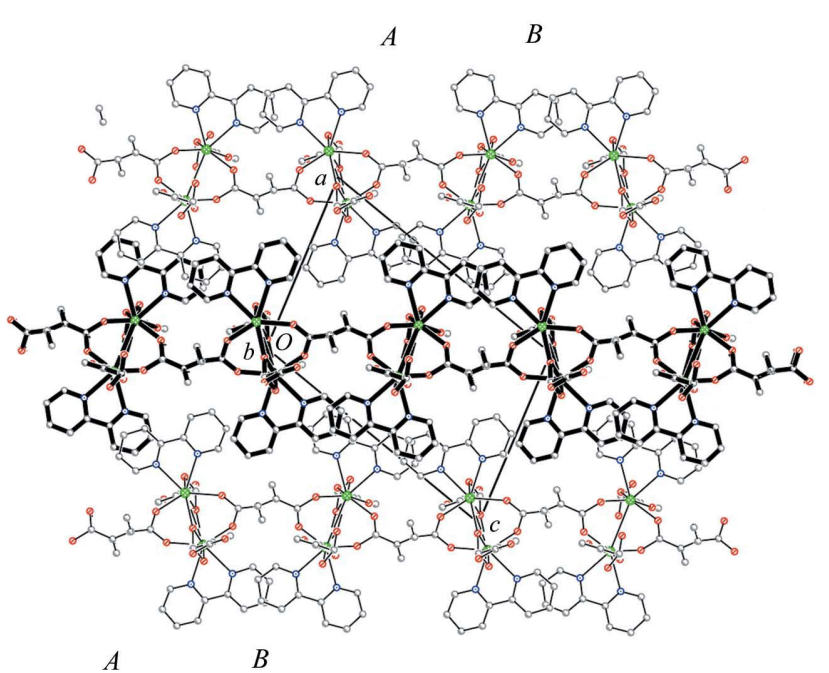

Figure 2

(b)

Packing views of (I), showing ( $a$ ) the binding modes displayed by ita3 and ita5, and $(b)$ the binding mode displayed by ita4 and the interdigitation of the bpy groups. Gd1-only columns are along the $A-A$ lines and Gd2-only columns are along the $B-B$ lines. 


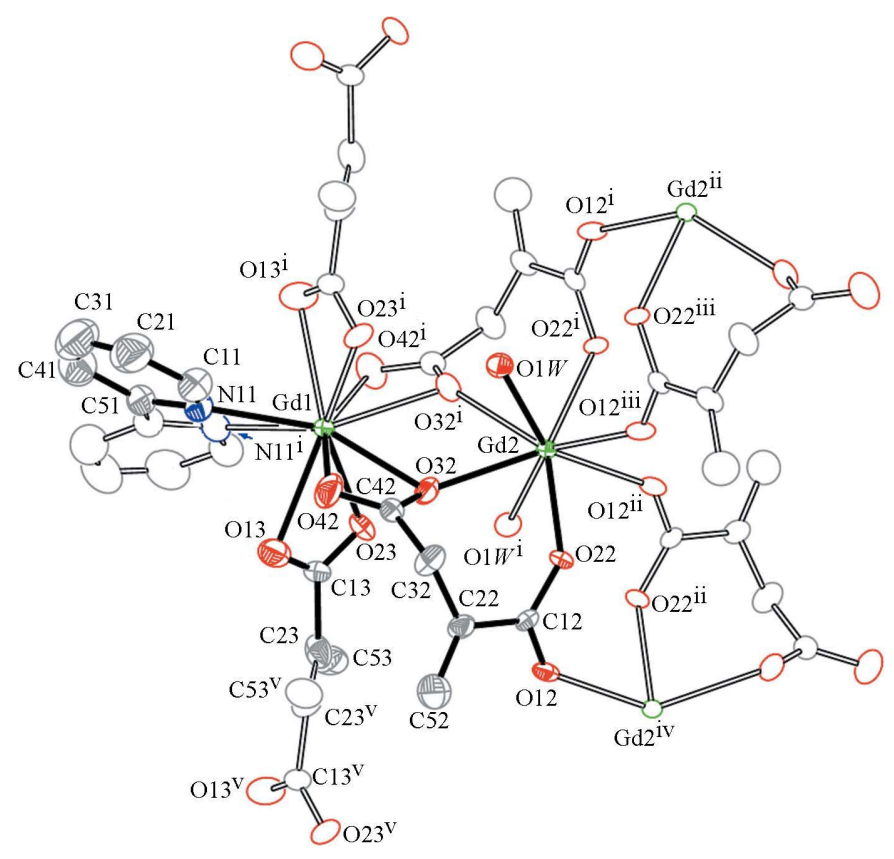

Figure 3

The elemental dimeric unit in (II), showing the atom-numbering scheme. Displacement ellipsoids are drawn at the $30 \%$ probability level and $\mathrm{H}$ atoms have been omitted for clarity. [Symmetry codes: (i) $-x+1, y,-z+\frac{1}{2}$; (ii) $-x+1,-y+1,-z$; (iii) $x,-y+1, z+\frac{1}{2}$; (iv) $-x+1,-y+1,-z+1$; (v) $-x+1, y,-z-\frac{1}{2}$.]

itaconate (ita) as the stabilizing anion and bipyridine (bpy) as an ancillary ligand. Unfortunately, and in spite of having attempted the synthesis with a diversity of lanthanides, the process only afforded crystals for $\mathrm{Ln}=\mathrm{Gd}$ [two different phases, compounds (I) and (II)] and Ho [compound (III)], and in all three cases the colourless thin rectangular plates obtained proved to be multiple or twinned to a greater or lesser degree. The results presented here are the outcome of a laborious and painstaking sample screening, which afforded the few crystals amenable to a full crystallographic study. However, the residual effects of twinning were evident in the requirement for a large number of restraints in order to refine successfully the models obtained, as well as in the large residual electron density found in the final difference electrondensity maps. In spite of these drawbacks, the structures obtained appear quite reasonable and they provide a rich survey of (at least qualitative) crystallographic results, in particular a new, hitherto unreported, coordination mode for the ita anion (coordination mode 11).

Tables 1, 2 and 3 present some relevant structural parameters for the three structures, while intermolecular interactions are surveyed in Tables 4 and 5 .

Compound (I), $\left[\mathrm{Gd}_{2}(\mathrm{ita})_{3}(\text { bpy })_{2}\right] \cdot 4 \mathrm{H}_{2} \mathrm{O}$, is shown in Fig. 1. It presents a two-dimensional polymeric structure built up around two independent $\mathrm{Gd}$ centres displaying similar $\mathrm{GdO}_{7} \mathrm{~N}_{2}$ environments, with both $\mathrm{N}$-donor atoms in each provided by a chelating bpy unit. The coordinating $\mathrm{O}$ atoms are from three different ita anions, which act in two well differentiated ways. (In the following discussion, the final digits of the atom labels are associated with a particular group

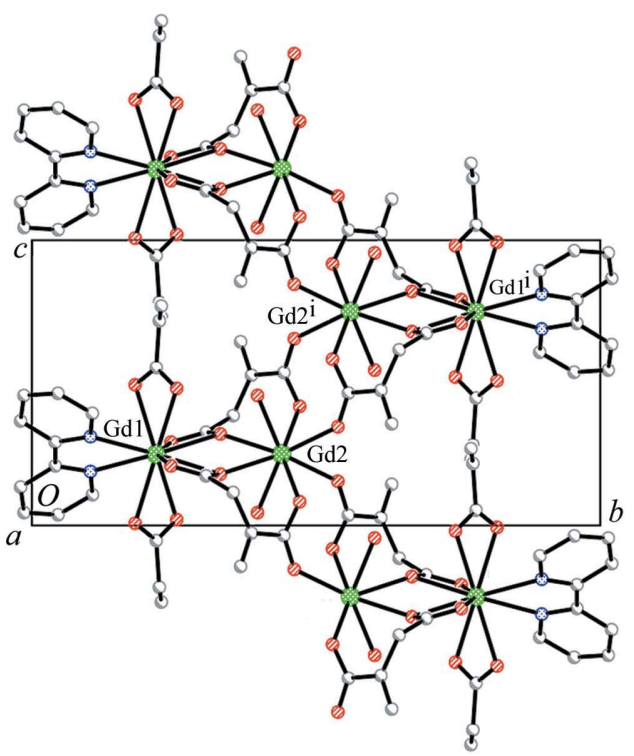

(a)

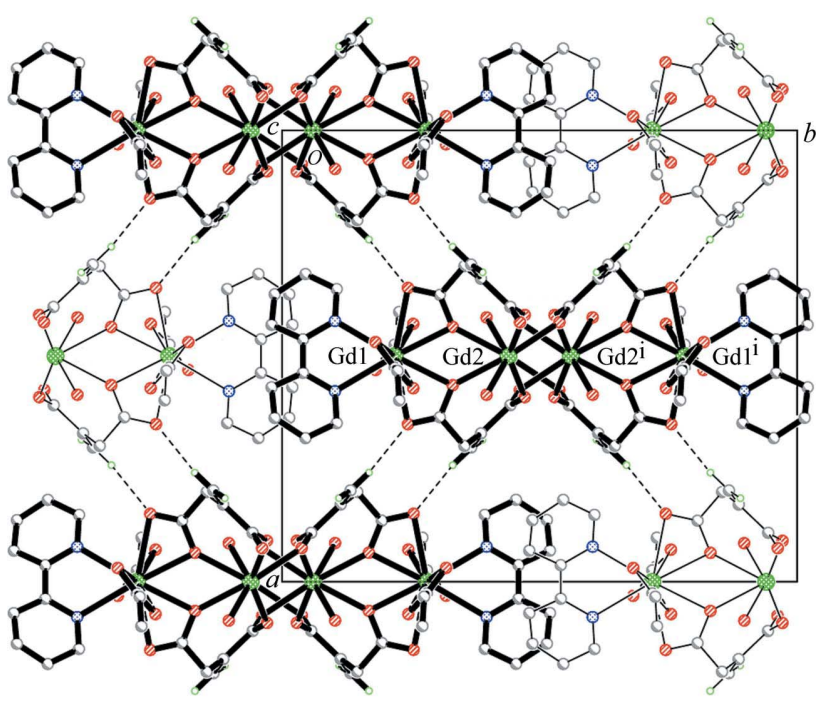

(b)

Figure 4

Packing views of (II), showing (a) the formation of the broad strips running along $c$ and $(b)$ their mutual interactions, viewed down the strip direction. [Symmetry code: (i) $\frac{1}{2}-x, \frac{1}{2}-y, 1-z$.]

of atoms; for example, atoms $\mathrm{C} 13-\mathrm{C} 53 / \mathrm{O} 13-\mathrm{O} 43$ are associated with the ita3 anion.)

Ita3 and ita5 (Fig. $2 a$ ) present a $\mu_{3}-O, O^{\prime}: O^{\prime \prime}, O^{\prime \prime \prime}: O^{\prime \prime \prime}$ binding mode (coordination mode 4), bridging three symmetry-related $\mathrm{Gd}$ centres of the same sort each, i.e. ita5 to atoms $\mathrm{Gd} 1$ and ita 3 to atoms $\mathrm{Gd} 2$. The bridging effect of these two anions is to generate columnar arrays of centrosymmetric dimers made up of either $\mathrm{Gd} 1$ or $\mathrm{Gd} 2$ coordination polyhedra, respectively, parallel to $b$ (vertical arrays in Fig. 2a)

Ita4 (Fig. $2 b$ ) presents a $\mu_{4}-O: O^{\prime}: O^{\prime \prime}: O^{\prime \prime \prime}$ coordination mode (7, see scheme) and joins neighbouring columns of different kinds through transverse bridging, i.e. $\mathrm{Gd} 1$ columns are joined to $\mathrm{Gd} 2$ columns (horizontal arrays in Fig. $2 a$ ), to generate the above-mentioned two-dimensional polymeric structure 




Figure 5

The centrosymmetric dimeric unit in (III), showing the atom-numbering scheme. Displacement ellipsoids are drawn at the $30 \%$ probability level and $\mathrm{H}$ atoms have been omitted for clarity. [Symmetry codes: (i) $-x+2$, $-y+1,-z+1$; (ii) $-x+2,-y,-z+1$; (iii) $x, y+1, z$; (iv) $-x+2, y$, $-z+\frac{1}{2}$.]

parallel to (011). The hydrophobic aromatic bpy groups stretch outwards, enlarging these sheets on both sides, and lead to interdigitation between neighbouring sheets (Fig. 2b), resulting in rather short interplanar $\pi-\pi$ distances (Table 4).

Compound (II), $\left[\mathrm{Gd}_{2}(\mathrm{ita})_{3}\left(\right.\right.$ bpy) $\left.\left(\mathrm{H}_{2} \mathrm{O}\right)_{2}\right]$, is shown in Fig. 3. This second gadolinium phase also presents two independent Gd centres, but the overall formula and individual coordination are different. The chemical unit in this case comprises two Gd cations, one bpy ligand, three ita anions and two aqua ligands, to give the chemical formula shown above, but since the whole structure is built up around a twofold axis passing through both cations, as well as through the centre of the bpy ligand and one of the ita anions (ita3), only half of the chemical unit is independent $\left(Z^{\prime}=0.5\right)$. The fact that the nonsymmetric ita3 anion is bisected by the twofold axis implies disorder in the $\mathrm{C}=\mathrm{CH}_{2}$ group, similar to the case of the homonymous anion in structure (III).

In contrast to (I), the two coordination polyhedra of (II) are completely different from each other (Fig. 3). Gd1 is tencoordinated by five chelating ligands, one bpy and four carboxylate groups from two pairs of symmetry-related ita2 and ita3 groups (coordination mode 4). Through the sharing of two symmetry-related $\mathrm{O}$ atoms acting in a $\mu_{2}$ fashion [O32 and O32 $2^{\text {; }}$ symmetry code: (i) $-x+1, y,-z+\frac{1}{2}$ ], Gd1 interacts with its sole gadolinium nearest neighbour $[\mathrm{Gd} 1 \cdots \mathrm{Gd} 2=$ 4.114 (1) $\AA$ ]. Gd2 instead, presents two extra links to two of its symmetry-related images $\left[\mathrm{Gd} 2^{\mathrm{ii}}\right.$ and $\mathrm{Gd} 2^{\mathrm{iv}}$; symmetry codes: (ii) $-x+1,-y+1,-z$; (iv) $-x+1,-y+1,-z+1$ ] via four extended $\mathrm{Gd}-\mathrm{O}-\mathrm{C}-\mathrm{O}-\mathrm{Gd}$ bridges involving the $\mathrm{O} 22-$ C12-O12 carboxylate and three of its symmetry-related counterparts (see Fig. 3), leading to a $\mathrm{Gd} \cdots \mathrm{Gd}$ distance of 5.169 (1) $\AA$ and a new, hitherto unreported, $\mu_{3}-O, O^{\prime}$ :$O^{\prime}, O^{\prime \prime}: O^{\prime \prime \prime}$ binding mode for the ita2 anion (coordination

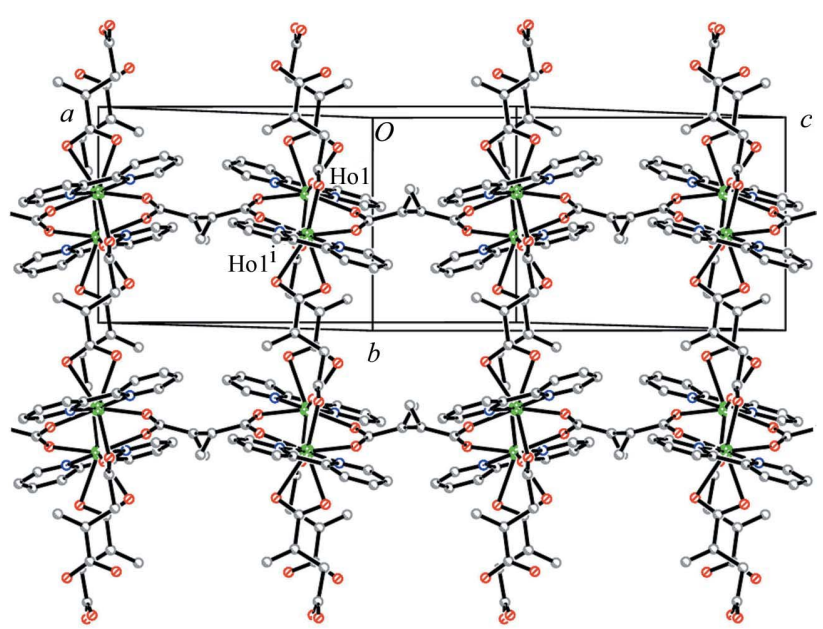

(a)

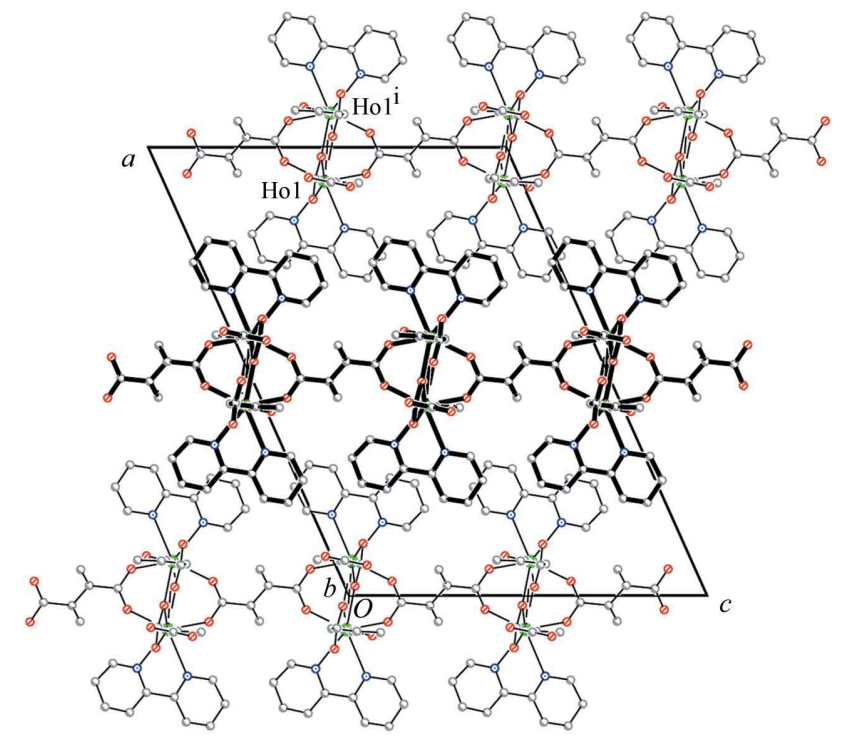

(b)

Figure 6

Packing views of (III), showing (a) the formation of chains running along $c$ and $(b)$ the two-dimensional arrays resulting from the chain linkage, drawn in projection along the chain direction (central array, appearing as a horizontal band, drawn with heavy lines for clarity). Bpy groups point outwards, interdigitating neighbouring structures. [Symmetry code: (i) $-x+2,-y+1,-z+1$.]

mode 11). Two water molecules complete an eightfold coordination of the cation (Fig. 3).

The tight linkage imposed by the ita ligands drives the formation of very broad strips, the width of four coordination polyhedra, which run along [001] (Fig. 4a). In these arrays, the hydrophobic bpy are located at the ribbon 'edges', so that the structures link laterally along [010] through interdigitation of the weakly interacting highly distorted bpy groups (pyridinepyridine dihedral angle $\left.=27.9^{\circ}\right)($ Fig. $4 b$ and Table 4$)$, to form a two-dimensional structure parallel to the (100) plane. The chains also interact at right angles to the latter contact, along [100], through a nonconventional $\mathrm{C} 52-\mathrm{H} 52 B \cdots \mathrm{O} 42\left(\frac{3}{2}-x\right.$, $\left.\frac{1}{2}-y,-z\right)$ hydrogen bond $[\mathrm{C}-\mathrm{H}=0.93 \AA, \mathrm{H} \cdots \mathrm{O}=$ 2.380 (19) $\AA$ and $\left.\mathrm{C}-\mathrm{H} \cdots \mathrm{O}=161^{\circ}\right]$. 
Compound (III), $\left[\mathrm{Ho}_{2}(\mathrm{ita})_{3}(\mathrm{bpy})_{2}\right] \cdot 4 \mathrm{H}_{2} \mathrm{O}$, is shown in Fig. 5. The structure presents a single independent cation (Ho1), a bpy unit and one and a half ita anions in the asymmetric unit, plus one nonbonded solvent water molecule (disordered into two sites), stabilizing the structure. These entities are disposed around a centre of symmetry as dimeric units of general formula $\left[\mathrm{Ho}_{2}(\mathrm{ita})_{3}(\mathrm{bpy})_{2}\right] \cdot 2 \mathrm{H}_{2} \mathrm{O}$, the cation being eight-coordinated by a chelating bpy and two chelating carboxylate groups from an ita2 unit and its [010] translational image (coordination mode 4), thus generating a chain structure along the $b$ axis, similar to (I). The difference arises in the way in which the two bridging $\mathrm{O}$ atoms of the remaining ita3 unit interact. The result is an array of chains running along $b$ made up of dimers bridged by ita2, and these chains are in turn interconnected sideways by the ligand ita3 (this straddles a twofold axis, resulting in disorder of the $\mathrm{C}=\mathrm{CH}_{2}$ group). Viewing the two-dimensional structure parallel to (100) shows the bpy pointing outwards (Fig. 6b) The two-dimensional structure parallel to (100) presents the bpy pointing outwards, so that interaction between sheets is provided, as in (I), by $\pi-\pi$ contacts between interdigitated aromatic rings.

Summarizing, in the structures reported here the itaconate ligand has again shown great coordination capability, giving rise to tightly interconnected structures, all of them polymeric. Compounds (I) and (III) present two-dimensional arrays further connected by weaker $\pi-\pi$ contacts, while compound (II) shows instead a broad strip-like formation packed via an assembly of diverse interactions. In compounds (II) and (III), in some of the itaconate ligands the $\mathrm{C}=\mathrm{CH}_{2}$ group is disordered across a symmetry element which is incompatible with the symmetry of the ligand. This is not an unusual feature in the anion, and it has already been found in many of the previously reported itaconate structures, viz. nickel itaconate (Burrows, Harrington et al., 2004), and many of the lanthanide itaconate complexes, viz. $\mathrm{Ln}=\mathrm{Eu}, \mathrm{Dy}, \mathrm{Er}$ and $\mathrm{Yb}$ (Liu et al., 2005).

\section{Experimental}

The reactants for the syntheses were the appropriate lanthanide oxides $\left(\mathrm{Gd}_{2} \mathrm{O}_{3}\right.$ or $\left.\mathrm{Ho}_{2} \mathrm{O}_{3}, 5.0 \times 10^{-4} \mathrm{~mol}\right)$, itaconic acid $(1.5 \times$ $10^{-3} \mathrm{~mol}$ ) and 2,2'-bipyridine (5.0 or $\left.10.0 \times 10^{-4} \mathrm{~mol}\right)$, corresponding to a molar ratio of 1:3:2 for (I) and 1:3:1 for (II) and (III). Starting materials were used as purchased without further purification. The mixture of the corresponding oxide in $\mathrm{H}_{2} \mathrm{O}(50 \mathrm{ml})$ was heated under reflux for about $30 \mathrm{~min}$, after which the itaconic acid was added, followed by the bpy. The order of addition is significant: on reversing the order, no reaction occurs. On standing, colourless crystals for the gadolinium complexes and pink for the holmium complex appeared. In all three cases, the crystals obtained were multiple to a larger or smaller degree, necessitating a lengthy screening process to find the most suitable (though far from perfect) crystals for X-ray diffraction analysis. The first two compounds came out formulated as planned in the synthesis, i.e. in 1:3:2 and 1:3:1 ratios, respectively. Compound (III) instead appeared in a 1:3:2 ratio, with a doubling of the (expected) bpy content. Hydrothermal methods were also tried in an unsuccessful search for better specimens.
Table 1

Selected bond lengths $(\AA)$ for $(I)$.

\begin{tabular}{llll}
\hline $\mathrm{Gd} 1-\mathrm{O} 35^{\mathrm{i}}$ & $2.346(7)$ & $\mathrm{Gd} 2-\mathrm{O} 34$ & $1.983(7)$ \\
$\mathrm{Gd} 1-\mathrm{O} 24$ & $2.346(8)$ & $\mathrm{Gd} 2-\mathrm{O} 44^{\mathrm{iii}}$ & $2.304(8)$ \\
$\mathrm{Gd} 1-\mathrm{O} 14^{\mathrm{i}}$ & $2.358(8)$ & $\mathrm{Gd} 2-\mathrm{O} 33^{\mathrm{iv}}$ & $2.347(7)$ \\
$\mathrm{Gd} 1-\mathrm{O} 25^{\mathrm{ii}}$ & $2.426(8)$ & $\mathrm{Gd} 2-\mathrm{O} 23$ & $2.456(8)$ \\
$\mathrm{Gd} 1-\mathrm{O} 15^{\mathrm{ii}}$ & $2.489(9)$ & $\mathrm{Gd} 2-\mathrm{O} 13$ & $2.487(9)$ \\
$\mathrm{Gd} 1-\mathrm{O} 45$ & $2.514(8)$ & $\mathrm{Gd} 2-\mathrm{O} 43^{\mathrm{ii}}$ & $2.496(7)$ \\
$\mathrm{Gd} 1-\mathrm{N} 11$ & $2.580(11)$ & $\mathrm{Gd} 2-\mathrm{N} 22$ & $2.542(11)$ \\
$\mathrm{Gd} 1-\mathrm{N} 21$ & $2.600(11)$ & $\mathrm{Gd} 2-\mathrm{N} 12$ & $2.621(10)$ \\
$\mathrm{Gd} 1-\mathrm{O} 35$ & $2.713(8)$ & $\mathrm{Gd} 2-\mathrm{O} 33^{\mathrm{ii}}$ & $2.679(8)$ \\
$\mathrm{Gd} 1-\mathrm{Gd} 1^{\mathrm{i}}$ & $3.9748(13)$ & $\mathrm{Gd} 2-\mathrm{Gd} 2^{\mathrm{iii}}$ & $3.9573(19)$ \\
\hline
\end{tabular}

Symmetry codes: (i) $-x+1,-y,-z$; (ii) $x+1, y, z$; (iii) $-x+1,-y+1,-z-1$; (iv) $-x,-y+1,-z-1$.

\section{Compound (I)}

Crystal data

$\left[\mathrm{Gd}_{2}\left(\mathrm{C}_{5} \mathrm{H}_{4} \mathrm{O}_{4}\right)_{3}\left(\mathrm{C}_{10} \mathrm{H}_{8} \mathrm{~N}_{2}\right)_{2}\right] \cdot 4 \mathrm{H}_{2} \mathrm{O}$

$M_{r}=1083.18$

Triclinic, $P \overline{1}$

$a=9.5507(19) \AA$

$b=12.598(3) \AA$

$c=17.582(4) \AA$

$\alpha=71.60(3)^{\circ}$

$\beta=82.32(3)^{\circ}$

\section{Data collection}

Bruker SMART-NT CCD areadetector diffractometer

Absorption correction: multi-scan (SADABS in SAINT-NT; Bruker, 2002)

$T_{\text {min }}=0.50, T_{\text {max }}=0.75$

Refinement

$R\left[F^{2}>2 \sigma\left(F^{2}\right)\right]=0.075$

$w R\left(F^{2}\right)=0.204$

$S=0.99$

6922 reflections

512 parameters

\section{Compound (II)}

\section{Crystal data}

$\left[\mathrm{Gd}_{2}\left(\mathrm{C}_{5} \mathrm{H}_{4} \mathrm{O}_{4}\right)_{3}\left(\mathrm{C}_{10} \mathrm{H}_{8} \mathrm{~N}_{2}\right)\left(\mathrm{H}_{2} \mathrm{O}\right)_{2}\right]$

$M_{r}=890.96$

Monoclinic, $C 2 / c$

$a=16.427(5) \AA$

$b=18.645(5) \AA$

$c=9.300$ (3) $\AA$

$\beta=94.949$ (6)

\section{Data collection}

Bruker SMART-NT CCD areadetector diffractometer

Absorption correction: multi-scan (SADABS in SAINT-NT; Bruker, 2002)

$T_{\text {min }}=0.25, T_{\max }=0.62$

Refinement

$R\left[F^{2}>2 \sigma\left(F^{2}\right)\right]=0.066$

$w R\left(F^{2}\right)=0.145$

$S=1.06$

3098 reflections

200 parameters $\gamma=68.39(3)^{\circ}$

$V=1865.9(9) \AA^{3}$

$Z=2$

Mo $K \alpha$ radiation

$\mu=3.60 \mathrm{~mm}^{-1}$

$T=293$ (2) K

$0.20 \times 0.15 \times 0.08 \mathrm{~mm}$

9794 measured reflections 6922 independent reflections 5639 reflections with $I>2 \sigma(I)$ $R_{\text {int }}=0.076$

541 restraints $\mathrm{H}$-atom parameters constrained $\Delta \rho_{\max }=7.16{\mathrm{e} \AA^{-3}}^{-3}$

$\Delta \rho_{\min }=-3.02 \mathrm{e}^{-3}$
$V=2837.7(14) \AA^{3}$

$Z=4$

Mo $K \alpha$ radiation

$\mu=4.71 \mathrm{~mm}^{-1}$

$T=293(2) \mathrm{K}$

$0.30 \times 0.25 \times 0.10 \mathrm{~mm}$

9298 measured reflections 3098 independent reflections 2689 reflections with $I>2 \sigma(I)$ $R_{\text {int }}=0.105$
150 restraints $\mathrm{H}$-atom parameters constrained $\Delta \rho_{\max }=1.83{\mathrm{e} \AA^{-3}}^{-3}$ $\Delta \rho_{\min }=-4.17{\mathrm{e} \AA^{-3}}^{-3}$ 
Table 2

Selected bond lengths $(\AA)$ for (II).

\begin{tabular}{llll}
\hline $\mathrm{Gd} 1-\mathrm{O} 23$ & $2.443(9)$ & $\mathrm{Gd} 1-\mathrm{Gd} 2$ & $4.1139(15)$ \\
$\mathrm{Gd} 1-\mathrm{O} 13$ & $2.456(9)$ & $\mathrm{Gd} 2-\mathrm{O} 22$ & $2.324(7)$ \\
$\mathrm{Gd} 1-\mathrm{O} 32$ & $2.464(7)$ & $\mathrm{Gd} 2-\mathrm{O} 12^{\mathrm{ii}}$ & $2.348(8)$ \\
$\mathrm{Gd} 1-\mathrm{N} 11$ & $2.551(11)$ & $\mathrm{Gd} 2-\mathrm{O} 32$ & $2.394(8)$ \\
$\mathrm{Gd} 1-\mathrm{O} 42$ & $2.585(10)$ & $\mathrm{Gd} 2-\mathrm{O} 1 W$ & $2.407(8)$
\end{tabular}

Symmetry code: (ii) $-x+1,-y+1,-z$.

Table 3

Selected bond lengths $(\AA)$ for (III).

\begin{tabular}{llll}
\hline Ho1-O23 & \\
Ho1-O13 & $2.298(7)$ & Ho1-O12 & $2.427(8)$ \\
Ho1-O32 & $2.303(8)$ & Ho1-N21 & $2.579(9)$ \\
Ho1-O42 & $2.310(7)$ & Ho1-N11 & Ho1-O32 \\
Ho1-O22 & $2.421(8)$ & iii & $2.690(10)$ \\
& $2.425(9)$ & Ho1-Ho1 & $3.967(2)$
\end{tabular}

Symmetry codes: (i) $-x+2,-y+1,-z+1$; (ii) $-x+2,-y,-z+1$; (iii) $x, y+1, z$.

Table 4

$\pi-\pi$ contacts $\left(\AA,^{\circ}\right)$ for (I), (II) and (III).

For (I), $C g 11$ is the centroid of the N11/C11-C51 ring, $C g 12$ is the centroid of the N12/C12-C52 ring and $\mathrm{Cg} 22$ is the centroid of the N22/C62-C102 ring. For (II), Cg11 is the centroid of the N11/C11-C51 ring. For (III), Cg11 is the centroid of the N11/C11-C51 ring. $<C g$-Perp $>$ is the average distance from one ring centre to the opposite ring; for details, see Janiak (2000).

\begin{tabular}{lllll}
\hline Compound & $C g 1 / C g 2$ & Dihedral angle & $C g 1 \cdots C g 2$ & $<C g$-Perp $>$ \\
\hline (I) & $C g 11 / C g 12^{\mathrm{i}}$ & $4.9(9)$ & $3.548(9)$ & $3.22(2)$ \\
& $C g 11 / C g 22^{\mathrm{ii}}$ & 3.63 & $3.703(9)$ & $3.21(3)$ \\
& $C g 12 / C g 22^{\mathrm{iii}}$ & $2.3(9)$ & $3.522(9)$ & $3.17(3)$ \\
(II) & $C g 11 / C g 11^{\mathrm{iv}}$ & 0.00 & $4.660(10)$ & $3.51(1)$ \\
(III) & $C g 11 / C g 11^{\text {iv }}$ & 0.00 & $3.801(10)$ & $3.44(1)$ \\
\hline
\end{tabular}

Symmetry codes: (i) $1-x, 1-y,-z$; (ii) $-x,-1+y, 1+z$; (iii) $-x, 2-y,-1-z$; (iv)

$1-x,-y, 1-z ;\left(\right.$ v) $\frac{3}{2}-x, \frac{1}{2}-y, 1-z$

\section{Compound (III)}

\section{Crystal data}

$\left[\mathrm{Ho}_{2}\left(\mathrm{C}_{5} \mathrm{H}_{4} \mathrm{O}_{4}\right)_{3}\left(\mathrm{C}_{10} \mathrm{H}_{8} \mathrm{~N}_{2}\right)_{2}\right] \cdot 2 \mathrm{H}_{2} \mathrm{O}$

$M_{r}=1062.51$

Monoclinic, $C 2 / c$

$a=25.023(5) \AA$

$b=9.3994(19) \AA$

$c=18.229$ (4) $\AA$

$\beta=114.13(3)^{\circ}$

\section{Data collection}

Bruker SMART-NT CCD areadetector diffractometer

Absorption correction: multi-scan ( $S A D A B S$ in SAINT-NT Bruker, 2002)

$T_{\min }=0.28, T_{\max }=0.54$

\section{Refinement}

$R\left[F^{2}>2 \sigma\left(F^{2}\right)\right]=0.079$

$w R\left(F^{2}\right)=0.223$

$S=1.00$

4299 reflections

263 parameters
Table 5

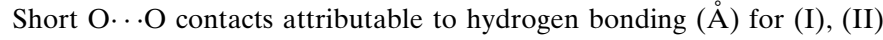
and (III).

\begin{tabular}{llll}
\hline Compound & $\mathrm{O} X$ & $\mathrm{O} Y$ & $\mathrm{O} X \cdots \mathrm{O} Y$ \\
\hline (I) & $\mathrm{O} 1 W$ & $\mathrm{O} 15^{\mathrm{i}}$ & $2.845(8)$ \\
& $\mathrm{O} 1 W$ & $\mathrm{O} W W$ & $2.749(8)$ \\
& $\mathrm{O} 2 W$ & $\mathrm{O} 23$ & $2.869(9)$ \\
& $\mathrm{O} 2 W$ & $\mathrm{O} 3 W$ & $2.897(10)$ \\
& $\mathrm{O} 2 W$ & $\mathrm{O} 4 W$ & $2.973(11)$ \\
& $\mathrm{O} 3 W$ & $\mathrm{O} 13^{\mathrm{ii}}$ & $2.901(9)$ \\
& $\mathrm{O} 4 W$ & $\mathrm{O} 45^{\mathrm{iii}}$ & $3.016(9)$ \\
(II) & $\mathrm{O} 1 W$ & $\mathrm{O} 22^{\mathrm{iv}}$ & $2.730(12)$ \\
& $\mathrm{O} 1 W$ & $\mathrm{O} 23^{\mathrm{v}}$ & $2.673(12)$ \\
(III) & $\mathrm{O} 1 W$ & $\mathrm{O} 2 W^{\mathrm{vi}}$ & $2.656(12)$ \\
& $\mathrm{O} 1 W$ & $\mathrm{O} 22$ & $2.956(13)$ \\
& $\mathrm{O} 2 W$ & $\mathrm{O} 12$ & $3.042(13)$ \\
\hline
\end{tabular}

Symmetry codes: (i) $-x,-y,-z$; (ii) $-x, 1-y,-1-z$; (iii) $-x, 1-y,-z$; (iv) $x, 1-y$, $\frac{1}{2}+z ;(\mathrm{v}) 1-x, y, \frac{1}{2}-z ;$ (vi) $x,-y, \frac{1}{2}+z$.

As already stated, the specimens were multiply twinned in a way that made it impossible to find an adequate twin law to separate them. However, in the three crystals finally chosen for data collection, it was possible, by using an appropriate orientation matrix, to isolate the main contribution to the diffraction and integrate it separately. This worked well for structures (II) and (III), but less so for structure (I), where severe overlap forced the rejection of a significant fraction of the data set ( $c$ 13\%); in the remaining two structures, the final integrated fraction at a level of $2 \theta=50^{\circ}$ was almost unity.

Structure solution was in all cases straightforward by standard direct methods, but refinement was only possible by applying similarity restraints to (expected) similar bonds and angles in different ligands. The number of restraints required was directly linked to the degree of difficulty found in the refinement of each structure. Thus, (I) required the full power of the SHELXL97 package (Sheldrick, 2008) by way of instructions SADI, DELU and SIMU, and in a few pathological cases (as for atoms O23, O25, O34, C43 and C45), ISOR, DFIX and DANG. Structures (II) and (III), instead, required milder restrictions.

The residual problems resulting from poor data quality were evident in the high $R$ values obtained, the extreme SHELXL97 weighting schemes and the extrema in the difference electron-density

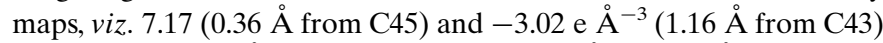

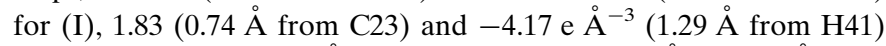

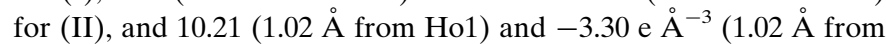
H81) for (III).

$\mathrm{C}$-bound $\mathrm{H}$ atoms were placed in their expected positions and allowed to ride in both coordinates $(\mathrm{C}-\mathrm{H}=0.93-0.97 \AA)$ and isotropic displacement parameters $\left[U_{\text {iso }}(\mathrm{H})=1.2\right.$ or $\left.1.5 U_{\text {eq }}(\mathrm{C})\right]$. $\mathrm{O}$-bound $\mathrm{H}$ atoms could not be found and were not included in the model.

For all compounds, data collection: SMART-NT (Bruker, 2001); cell refinement: SAINT-NT (Bruker, 2002); data reduction: SAINT$N T$; program(s) used to solve structure: SHELXS97 (Sheldrick, 2008); program(s) used to refine structure: SHELXL97 (Sheldrick, 2008); molecular graphics: SHELXTL-NT (Sheldrick, 2008); software used to prepare material for publication: SHELXTL-NT and PLATON (Spek, 2003).

The authors acknowledge the Spanish Research Council (CSIC) for providing a free-of-charge licence to the Cambridge Structural Database, and are also grateful for funding by the project Fondecyt (grant No. 1070298).
34 restraints

$\mathrm{H}$-atom parameters constrained

$\Delta \rho_{\max }=10.21{\mathrm{e} \AA^{-3}}^{-3}$

$\Delta \rho_{\min }=-3.30{\mathrm{e} \AA^{-3}}^{-3}$ 


\section{References}

Allen, F. H. (2002). Acta Cryst. B58, 380-388.

Briceño, A., Diaz de Delgado, G., Ramirez, B., Velasquez, W. O. \& Bahsas, A. (1999). J. Chem. Crystallogr. 29, 785-791.

Bruker (2001). SMART-NT. Version 5.624. Siemens Analytical X-ray Instruments Inc., Madison, Wisconsin, USA.

Bruker (2002). SAINT-NT. Version 6.22a (including SADABS). Siemens Analytical X-ray Instruments Inc., Madison, Wisconsin, USA.

Burrows, A. D., Donovan, A. S., Harrington, R. W. \& Mahon, M. F. (2004). Eur. J. Inorg. Chem. pp. 4686-4695.

Burrows, A. D., Harrington, R. W., Mahon, M. F. \& Teat, S. J. (2004). Cryst. Growth Des. 4, 813-822.

Contreras, J. E., Ramirez, B. \& Diaz de Delgado, G. (1997). J. Chem. Crystallogr. 27, 391-395.

Eddaoudi, M., Moler, D. B., Li, H., Chen, B., Reineke, T. M., O'Keeffe, M. \& Yaghi, O. M. (2001). Acc. Chem. Res. 34, 319-330.

Janiak, C. (2000). J. Chem. Soc. Dalton Trans. pp. 3885-3898.

Liu, C. B., Yu, M. X., Zheng, X. J., Jin, L. P., Gao, S. \& Lu, S. Z. (2005). Inorg. Chim. Acta, 358, 2687-2696.

Seo, J. S., Whang, D., Hyoyoung, L., Jun, S. I., Oh, J., Jeon, Y. J. \& Kim, K. (2000). Nature (London), 404, 982-986.

Sheldrick, G. M. (2008). Acta Cryst. A64, 112-122.

Spek, A. L. (2003). J. Appl. Cryst. 36, 7-13.

Yaghi, O. M., Li, H. \& Groy, T. L. (1997). Inorg. Chem. 36, 4292-4293.

Yaghi, O. M., O'Keeffe, M., Ockwig, N. W., Chae, H. K., Eddaoudi, M. \& Kim, J. (2003). Nature (London), 423, 705-714.

Zhang, G., Yang, G. \& Ma, J. S. (2006). Cryst. Growth Des. 6, 933-939. 